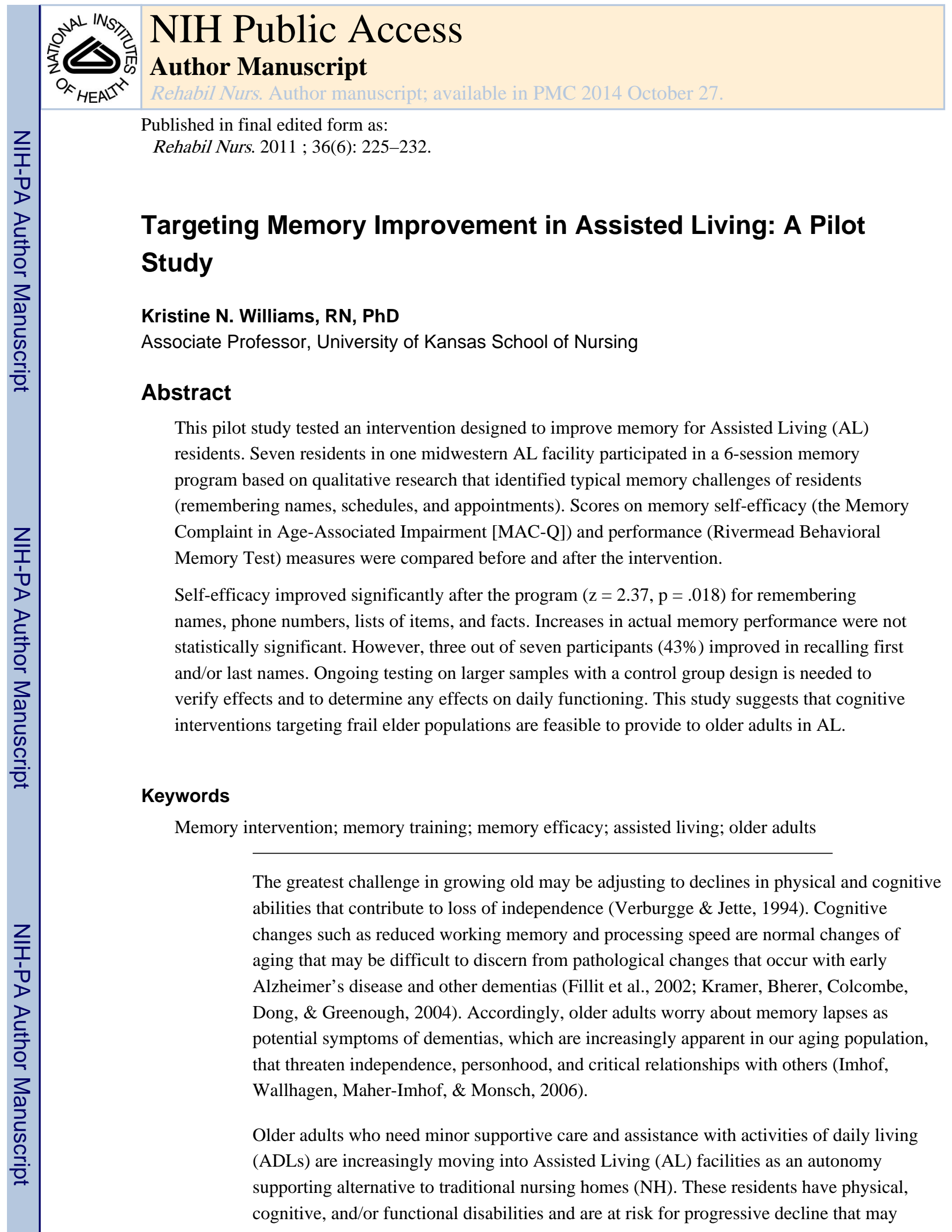

Address correspondence to Kristine N. Williams, RN, PhD, University of Kansas School of Nursing, 3901 Rainbow Blvd., Kansas City, KS 66160-7502, phone (913) 588-1624, fax (913) 588-1660, kwilliams1@ kumc.edu. 
increase their care needs above the threshold of self-care needed to remain in AL. Many residents worry about cognitive declines when they observe that it precipitates $\mathrm{NH}$ placement in fellow residents (Aud \& Rantz, 2005; Williams \& Warren, 2008) .

Worry about memory loss was expressed by the majority of a group of residents who were interviewed about their AL experiences (Marchant \& Williams, 2009; Williams \& Warren, 2009). Memory interventions have been effective in improving memory performance in healthy, community dwelling older adults (Rebok, Carlson, \& Langbaum, 2007; Saczynski, Willis, \& Schaie, 2002). However, only limited research has tested cognitive interventions for AL residents (McDougall, 2000; Williams, 2008).

The goal of this pilot study was to test the feasibility and effect of Memory Exercises in Assisted Living (MEAL), a new intervention targeting common memory challenges reported by AL residents. The intervention was based on the findings of a qualitative study, reported elsewhere, that identified memory issues for this population of older adults (Marchant \& Williams, 2009). This study demonstrates how cognitive training can be targeted to meet the needs of special populations of frail elders. Improved memory performance may also support self-care functioning, thus potentially extending AL residency.

\section{ASSISTED LIVING}

As the fastest growing residential care option, AL facilities currently house 1 million older adults and are estimated to expand two-fold over the next decade (Mollica \& JohnsonLemarche, 2005; National Center for Assisted Living, 2007). AL residents need minimal assistance with meal preparation, personal care, medication administration, and housekeeping, enabling them to live in private apartments (in contrast to $\mathrm{NH}$ care). Despite goals of maintaining independence and autonomy, these residents are at risk for cognitive decline, functional disability, and depression that require more intensive and costly $\mathrm{NH}$ care (Aud \& Rantz, 2005; Maas \& Buckwalter, 2006; Zimmerman et al., 2005).

AL residents require assistance with an average of 2.3 ADLs compared to 3.8 ADLs for NH residents (National Center for Assisted Living, 2007). Interventions that limit decline in cognitive performance and promote self-care may permit elders to extend their residency and delay $\mathrm{NH}$ placement. Memory lapses, such as forgetting to attend meals, could signal a need for a higher level of care and supervision provided in a NH. Not only is NH placement dreaded, but $\mathrm{NH}$ care is twice as costly. A national trade survey estimates average annual $\mathrm{NH}$ costs for a shared room at $\$ 74,808$ compared to $\$ 36,573$ for a private AL apartment (Genworth Financial, 2007).

\section{MEMORY TRAINING}

Memory loss is a great concern for older adults, including those in AL. Increased awareness of Alzheimer's disease and other dementias may contribute to fear of memory loss. "Brain health" programs developed by aging interest groups such as the American Association of Retired Persons (AARP, 2004) and the Alzheimer's Association (Alzheimer's Association, 2006) provide directives for nutrition, physical and cognitive activities, and other lifestyle modifications to enhance older adults' cognition and memory. Computer training, memory 
tapes, and Nintendo games are marketed to the lay public with claims of enhancing cognition, assuming that "use it or loose it" applies to cognition as well as physical health (Casel, 2002). These products provide evidence of the growing interest in preventive cognitive training for aging adults.

Cognitive training interventions also show promise for persons with mild dementia and cognitive decline. A meta-analysis of cognitive training research involving persons with Alzheimer's disease recently reported overall effect sizes of 0.47 for a variety of interventions that improved learning, memory, executive functions, ADLs, general cognitive problem solving, depression, and self-rated functioning (Sitzer, Twamley, \& Jeste, 2006). This meta-analysis suggests that the increasing population of AL residents with mild cognitive decline may benefit from cognitive interventions.

A national randomized clinical trial, the Advanced Cognitive Training in Vital Elders (ACTIVE) study, documented that memory training immediately improved memory performance in older adults living independently in the community (Ball et al., 2002). However, beneficial effects were limited to older adults without significant memory declines prior to the start of trainining (Unverzagt et al., 2007). Additional studies have replicated the beneficial effect of memory training for persons with mild cognitive impairments (Craik et al., 2007) and with Alzheimer's disease (Yu, Kolanowski, Strumpf, \& Eslinger, 2006)

\section{DESIGN AND METHODS}

A quasi-experimental pretest/posttest design was used to test the feasibility of the Memory Exercises in Assisted Living (MEAL) intervention for older adults in one AL facility. Resident volunteers participated in the individual MEAL training sessions with the investigators, which were provided twice weekly over a 3-week period in sessions lasting approximately 60 minutes. The six-session intervention was preceded and followed by individual assessments lasting less than 60 minutes to evaluate subjective and objective memory performance as well as descriptive factors. Subjective comments about the training program also were elicited from the participants to evaluate and modify the MEAL program.

Following approval by the investigator's university Human Subjects Protection Committee, subjects were recruited from a 40-bed AL unit; part of a Continuous Care Retirement Community (CCRC) located in a major Midwestern metropolitan area. The investigator presented an overview of the study at a neighborhood meeting. Those residents expressing interest in the study were later contacted individually to explain the study in greater detail and to obtain signed informed consent. Inclusion criteria included the ability to communicate with the investigator in English and a Mini Mental Status Exam (MMSE) score of at least 24 (to assure comprehension of the training materials). Exclusion criteria included unstable medical status, limitations in communication on initial interview, unwilling/unable to provide signed informed consent, and planning to move from AL during the study. 


\section{MEAL INTERVENTION}

The MEAL intervention was developed to address concerns about memory and cognitive decline expressed by AL residents in prior research (Williams \& Warren, 2008; 2009).

Based on consensus concerns over memory loss, a second study used qualitative content analysis of guided interviews specifically focused on AL residents' memory experiences (Marchant \& Williams, 2009). That study identified perceptions of memory limitations and priority memory training needs. AL residents were challenged in remembering names of multiple staff and fellow residents as well as complex AL activity schedules and appointments.

The Health Belief Model (Becker, 1974), the conceptual framework for the study, guided the development of the MEAL intervention. Because of perceived susceptibility to serious cognitive decline, AL residents were receptive to learning and practicing new memory health behaviors to maintain or improve memory, when presented with the research study opportunity.

A total of six sessions were developed based on prior memory training research in community dwelling populations (ACTIVE) and successful cognitive training provided to AL populations (McDougall, 2000; Williams, 2008; Willis et al., 2006). The training materials were reviewed and modified with input from experts in cognitive psychology, older adult education, and AL. All materials were assessed at a $5^{\text {th }}$ to $6^{\text {th }}$ grade FleschKincaid reading level. The content included limited didactic information and incorporated colorful illustrations, followed by application exercises specific to AL resident daily life.

A simple model of memory processing was used as a framework for understanding the process of memory formation, storage, and retrieval and to illustrate how memory strategies taught in the program overcome barriers to memory success. For example, careful attention and elimination of distractions are strategies to improve transfer of information from sensory memory to short term memory. Association is a strategy to improve encoding (and retrieval) from short term memory to long-term memory. A diagram of the model adapted from Teaching Memory Improvement to Adults (Fowgler \& Stern, 1994), is included in Figure 1.

Additional memory skills taught in the six sessions included association, visualization, active observation, elaboration, and use of external memory aides. Content and materials were adapted to the interests and pace of AL residents from established adult memory training materials (Fowgler \& Stern, 1994). Normal memory changes in aging were also discussed. An example exercise using association to recall names is provided in Figure 2.

The sessions were provided by the investigators in the resident's individual apartment at a time and day (twice weekly) convenient for the resident. The one-on-one interactions minimized the risk of trying new memory strategies. Prior to starting each session, investigators assured lighting adequacy, noise control, and availability of hearing aids and eyeglasses. Participants were encouraged to practice memory strategies between the sessions. Positive reinforcement was given for successful application of the memory strategies during the training exercises and for reports of practice between sessions. The training materials were presented in a workbook format, with colorful illustrations and large 
(20 point) font sizes. Costs of the intervention (including recruitment, travel and intervention time, and materials) were estimated at $\$ 400$ for each subject.

\section{DATA COLLECTION}

Demographic data, collected from each participant's medical record, included age; race and ethnicity; marital status; education; occupational background; months in AL residency; medical diagnoses; and existence of hearing, communication, and cognitive impairments. Pre- and post-training assessments of memory self-efficacy and objective memory performance were collected in separate 1-hour sessions 1 week prior to the first session and within 1 week of completing the sixth training session.

\section{MEASURES}

Memory self-efficacy was measured with the Memory Complaint in Age-Associated Memory Impairment Questionnaire (MAC-Q) (Crook, Feher, \& Larrabee, 1992). Objective memory performance was measured using the Rivermead Behavioural Memory Test (Cockburn \& Smith, 2003). Both of these measures have been used in populations of frail elders residing in institutions (Cockburn \& Collin, 1988; McDougall, 2000). To minimize potential bias, different investigators administered the two assessments and the second assessor was blinded to baseline scores. A trained research assistant scored the assessments and entered the deidentified data into secure computer files for analysis.

Secondary factors that may impact memory were assessed at baseline to describe the sample. These include demographic and functional status (extracted from the AL facility medical record), general cognition (MMSE), and social activity engagement (Assisted Living Social Activity Scale [AL-SAS] (Zimmerman et al., 2003). A program evaluation was completed at the final session.

\section{Self-efficacy}

The MAC-Q is a six-item self-report scale of perceived memory decline that takes approximately 15 minutes to administer to older adults. Participants rate their current memory in comparison to past performance for specific situations (names, numbers, object locations, facts, lists of items, and general memory). Ratings can range from "much better now" scored 1, to "much poorer now" scored 5. The final rating of general memory is double weighted. A lower score indicates self-reported improved memory performance.

Concurrent validity for scale use in a population with age-associated memory decline has been supported by significant correlations (range $r=.13$ to $.28, p<.001$ ) on six standard memory measures. MAC-Q scores have established as independent of depression scores (Hamilton Depression Scale). Internal consistency of the scale is satisfactory $(r=.7, p<$. 001 ) and test-retest reliability has been established at .71 for the total scale (Crook et al., 1992). 


\section{Objective Memory Performance}

The Rivermead Behavioural Memory Test was used as an objective measure of memory performance (Wilson, Cockburn, Baddeley, \& Hiorns, 2003). This assessment has been established as a reliable and valid performance-based measure of memory in older adult populations (Cockburn \& Collin, 1988; Wilson et al., 2003). The test takes approximately 30 minutes to complete and includes items such as recalling first and last names, recognizing pictures, reciting facts from a story, and being oriented to time and date. Immediate and delayed recall is tested. Because of the limited mobility of many of the subjects, one part of the assessment that involved ambulating through a series of steps in the room was modified. Instead of enacting a route themselves, participants manipulated a figurine in a doll house to follow a recalled route.

\section{Demographic Factors}

The state mandated Functional Capacity Screen, designed as an assessment for persons residing in licensed AL settings, was used to assess other factors that may impact memory abilities as well as an older adult's response to the intervention. Information including impairment of hearing, communication, cognition, and mental illnesses including depression are assessed by a licensed health care professional. Demographic data such as age, gender, marital status, education, and former occupation are also provided in the AL medical record.

A facility specific functional status tool for determining graduated costs for AL care was used as a measure of functional status. This staff completed data was extracted from the facility medical record and rates $28 \mathrm{ADL}$ and IADL activities on a four-point scale (ranging from "independent" to "total assist") with possible scores ranging from 0 to 51. Resident mean score is computed and assigned to a level of care, with 0 being minimal assistance and 4 being the greatest assistance from nursing staff.

\section{Mini Mental Status Exam}

The 10 minute Mini Mental Status Exam (MMSE) screening test evaluates general mental function and is used as a screening test for dementia with lower scores indicating reduced cognitive abilities (Folstein, Folstein, \& McHugh, 1975). Retest reliability correlations are established at above $\mathrm{r}=.80$ levels. It has established validity as a research tool for older adults residing in a variety of residential care settings and is useful to assess intervention effects on cognition (Kurlowicz \& Wallace, 1999).

\section{Assisted Living Social Activity Scale}

This 11-item Assisted Living Social Activity Scale (AL-SAS) was developed from existing surveys of elderly long-term care and community populations to assess resident social engagement in private and group activities and outings that can provide cognitive stimulation. It assesses activity participation during the past week. Reliability of the ALSAS is 0.74 (Zimmerman et al., 2003). 


\section{Program Evaluation}

Participants rated the MEAL program for helpfulness of the information, usefulness in everyday situations, effect on worry about solving problems, and willingness to recommend the program to others and to pay for attendance. A five-item Likert scale was adapted for this study to determine perceived helpfulness and willingness to recommend and pay for the intervention (Smith, Leenerts, \& Gajewski, 2004).

\section{PROCEDURES}

The study was initiated and the intervention provided during summer 2008. All participants maintained independent decision making capacity for care provided in the AL facility. Each completed a signed informed consent prior to participation and was assured of confidentiality and only aggregate reporting of results. Following completion of the six training sessions and pre- and post-assessment sessions, participants were presented with a $\$ 20$ money order honorarium. Descriptive data and nonparametric statistical comparison of baseline and post-interventions scores were computed using Wilcoxin Signed Ranks Tests because the small sample size prohibited assessment of normal distribution of data, an assumption for paired $t$ tests.

\section{RESULTS}

Seven AL residents were enrolled in the study and all completed the intervention sessions on schedule. All subjects were Caucasian except for one black male. Two participants were married and lived in AL with their spouse, one was divorced, and the remainder were widows or widowers. All participants completed high school and two subjects graduated from college. All subjects were retired. One male subject had been an executive; the other man was a truck driver. Three women had been homemakers, with one teacher and one registered nurse. None of the subjects had communication or uncompensated hearing impairments.

The participants' medical diagnoses included from two to ten chronic diseases per resident. Three had diagnoses of depression that were adequately treated with selective serotonin reuptake inhibitors. One participant was recently diagnosed with probable dementia and two residents were prescribed acetyl cholinesterase inhibitors to enhance cognitive function. The eight to thirteen medications prescribed for each resident were reviewed to assess for potential effects on memory performance. One participant was awaiting surgery for spinal stenosis and was taking two narcotics that may have adversely affected her cognitive function and one subject was prescribed an anticholinergic incontinence medication. See Table 1 for additional descriptive and demographic information about the participants.

\section{Memory Self-Efficacy Scores}

The Wilcoxin Signed Rank Test was used to analyze the data because it is appropriate to evaluate paired score differences on repeated continuous measure data when distributional assumptions for parametric tests are not met (Green, Salkind \& Akey, 2000. All the participants indicated an improvement in their memory self-efficacy after completing the MEAL training (see Table 2 and Figures 2 and 3). Possible scores on the MAC-Q 
assessment range from 7 to 35 with lower scores indicating improved memory. Total scores decreased from baseline $M=36.17, \mathrm{SD}=3.7$ to post-training $M=24.0, \mathrm{SD}=5.72, \mathrm{z}=2.37$, $p=.018$. Individual item scores for remembering names improved significantly from baseline $M=4.33, S D=.52$ to post-training $M=2.0, \mathrm{SD}=.9, \mathrm{z}=2.21, p=.027$. Remembering lists of items (such as a shopping list) improved from baseline $M=3.83, S D$ $=.41$, to post-training $M=2.17, S D=.75, \mathrm{z}=2.27, p=.023$. Recall of numbers and ratings of ability to remember facts and locations of objects (i.e., where keys were left) and general memory improved but was not statistically significant.

\section{Objective Memory Performance Scores}

No statistically significant differences occurred between baseline and post-training performance on the Rivermead assessment total scores except for the measure of orientation that improved from baseline $M=.57, S D=.54$ to post-training $M=1.43, \mathrm{SD}=.79, \mathrm{z}=$ 2.12, $p=.034$ (see Table 3). Trends occurred in improved performance on other measures. Forty-three per cent of participants had improved performance in remembering either first, last, or both names (this reflects 3 of the 7 participants).

\section{Program Evaluation}

Participants rated the helpfulness of information provided and helpfulness in everyday situations on a five-point Likert scale ranging from 1 "not helpful" to 5 "very helpful." Participants rated helpfulness with mean scores of 4.57 and 3.86 respectively. Effects on worry about memory loss mean scores were 1.86 on a scale of 1 as "less worry" to 5 as "more worry." Possible responses for the frequency of strategy use ranged from 1 "not used" to 5 "use daily." Participants rated this item $M=4.86$. Participants reported they would be willing to pay to attend the program and would recommend it to other AL residents.

\section{DISCUSSION}

This pilot study was a preliminary feasibility study that demonstrated that a memory training program can be provided to AL residents at minimal cost. AL residents rated the program highly and reported that they enjoyed learning that helped occupy their otherwise idle time. Several participants agreed to participate only if the sessions were provided to them individually (due to discomfort over disclosing their memory status to others). This could be a limiting factor for providing the MEAL training in group sessions, which are less costly. Format of the program presentation and costs should be evaluated in future research.

The gains in memory self-efficacy and reported frequency of memory strategy use are encouraging but must be interpreted with caution. Confidence in memory abilities may increase engagement in social activites in AL, which is associated with increasing psychological well-being (Soon Park, 2009). Learning memory strategies and practicing them in training sessions prepares the older adult to use a tool that may improve memory performance. Because of the small sample size, the paired $t$ test assumption of normally distributed data could not be assured. Replication with a larger sample and a control group is needed to assess the effects of the intervention and may also provide valuable information about other factors, such as medication use and physical activity that influence memory for 
these elders. Future research should also evaluate maintenance of effects over time and additional benefits such as psychological well-being and self-care.

The small sample size and reliance on the Rivermead assessment may have contributed to the lack of significant improvement in objective memory performance measure. The Rivermead assessment addresses a wide range of memory tasks, beyond the focus of the sixsession MEAL training program. Failure to improve over all these areas may be due to the limited focus of the MEAL training (focusing on remembering names, activity schedules, and appointments) that did not generalize to other memory applications. A more specific memory measure that reflects the emphasis of MEAL may be needed to truly assess program effects. Practice effects from application of these targeted skills during the training and during the repeated assessments may have contributed to improvement.

Because older adults are sensitive to acknowledging memory loss, they may be hesitant to participate in assessments that emphasize declines in their cognitive abilities. However, both the MAC-Q and Rivermead assessments were well received by participants and resulted in varied scores. The sample size limited the ability to evaluate relationships between depression, activity, general cognition, and the MAC-Q and Rivermead outcomes, these factors should all be explored in future research. Follow-up assessments will be important to determine whether skills and strategies are maintained over time or require booster sessions.

\section{IMPLICATIONS}

This pilot study established the feasibility of providing memory training for older adults in AL settings and suggests that these older adults benefit from targeted cognitive interventions. The preliminary success of this intervention supports the findings of a limited number of research studies testing cognitive interventions in AL populations (McDougall, 2000; Williams, 2008). AL residents may benefit psychologically from memory training, and nursing staff should include memory supportive interventions in their care. For example, staff could coach a resident through identification of an association to remember a fellow resident's name and then provide association specific cues in later recall situations. Staff could reintroduce themselves and new residents by name repeatedly to promote recall. Prompting residents to use external memory strategies such as lists and calendars also may promote memory success.

With mounting evidence of the role of cognition in self-care competency, cognitive interventions may prove effective at supporting personal care so that older adults can continue living independently or with limited supportive care such as AL, preventing premature nursing home placement (Willis et al., 2006; Salthouse). If memory and other cogntive training can effectively maintain self-care performance, widespread implementation could extend AL residency, currently only 1-3 years, saving approximately half the annual costs of $\mathrm{NH}$ care while honoring preferences of older adults (Aud \& Rantz, 2005; Genworth, 2007; Golant, 2004).

Education of nurses and other health care providers will need to increasingly focus on cognition and interventions to promote successful cognitive aging. Future care staff may include "cognitive aides," specifically trained paraprofessionals focused on cognitive health 
promotion and rehabilitation, complementing the current use of physical rehabilitation aides in long term care settings. Cognitive therapies may become an important part of care plans that can be tailored to individual resident needs.

Improved memory self-efficacy resulting from cognitive interventions such as MEAL could increase participation in social and recreational activities, contributing to improved quality of life for frail elders in AL and other care settings. Thus, formal memory training classes may also become a popular health promotion activity for older adults. Additional research testing memory and other cognitive interventions for older adults across community and institutional care settings is needed to develop cost effective evidence-based interventions to support cognitive aging. Ultimately, if maintained or improved memory contributes to selfcare, residents may be able to extend their length of stay in $\mathrm{AL}$ and avoid premature $\mathrm{NH}$ placement, reducing health care costs for our aging society.

\section{Acknowledgments}

Supported by the Building Interdisciplinary Research Careers in Women's Health (BIRCWH) K-12 Program HD052027 (P. Thomas, PI) at the Kansas University Medical Center, School of Medicine.

\section{References}

AARP. Staying sharp: Current advances in brain research. 2004. Retrieved September 6, 2006,http:// www.aarp.org/health/brain/program/staying_sharp_understanding_maintaining_your_brai.ht

Alzheimer's, Association. Maintain your brain. 2006. Retrieved September 8, 2006, from jttp:// www.alzrockymtn.org/maintain.asp

Andresen EM, Malmgren JA, Carter WB, Patrick DL. Screening for depression in well older adults: Evaluation of a short form of the CES-D. American Journal of Preventive Medicine. 1994; 10(2): 77-84. [PubMed: 8037935]

Aud MA, Rantz M. Admissions to skilled nursing facilities from assisted living facilities. Journal of Nursing Care Quality. 2005; 20(1):16-25. [PubMed: 15686073]

Ball K, Berch DB, Helmers KF, Jobe JB, Leveck MD, Marsiske M, et al. Effects of cognitive training interventions with older adults: A randomized controlled trial. Journal of the American Medical Association. 2002; 288(18):2271-2281. [PubMed: 12425704]

Becker MH. The Health Belief Model and personal health behavior. Health Education Monographs. 1974; 2:324-473.

Casel CK. Use it or lose it. Activity may be the best treatment for Aging. JOurnal of the American Medical Association. 2002; 288(18):2333-2334.

Cockburn J, Collin C. Measuring everyday memory in elderly people: A preliminary study. Age and Ageing. 1988; 17(4):265-269. [PubMed: 3177086]

Cockburn, J.; Smith, PT. The Rivermead Behavioural Memory Test. 2. London: Harcourt Assessment; 2003.

Craik FIM, Winocur G, Palmer H, Binns MA, Edwards M, Bridges K, et al. Cognitive rehabilitation in the elderly: Effects on memory. Journal of the International Neuropsychological Society. 2007; 13:132-142. [PubMed: 17166312]

Crook TH, Feher EP, Larrabee GJ. Assessment of memory complaint in age-associated memory impairment: The MAC-Q. International Psychogeriatrics. 1992; 4:165-175. [PubMed: 1477304]

Fillit H, Butler R, O'Connell A, Albert M, Birren J, Contman C, et al. Achieving and maintaining cognitive vitality with aging. Mayo Clinic Proceedings. 2002; 77(7):681-696. [PubMed: 12108606] 
Folstein MF, Folstein SE, McHugh PR. 'Mini Mental State': A practical method for grading the cognitive stat of patients for the clinician. Journal of Psychiatric Research. 1975; 12:189-198. [PubMed: 1202204]

Fowgler, J.; Stern, L. Teaching memory improvement to adults, Revised Edition. Baltimore: Johns Hopkins University Press; 1994.

Genworth Financial. Cost of Care Survey [Electronic Version]. 2007. Retrieved August 31 from http:// www.genworth.com

Golant S. Do impaired older persons with health care needs occupy U.S. assisted living facilities? An analysis of six national studies. Journals of Geronotology: Sociological Sciences. 2004; 59(2):S68-S79.

Green, SB.; Salkind, NJ.; Akey, TM. Using SPSS for Windows; Analyzing and understanding data. 2. Prentice Hall; Upper Saddle River, N.J: 2000.

Imhof L, Wallhagen M, Maher-Imhof R, Monsch A. Becoming forgetful: How elderly peoople deal with forgetfulness in everyday life. American Journal of Alzheimer's Disease \& Other Dementias. 2006; 21:347-353.

Kramer AF, Bherer L, Colcombe SJ, Dong W, Greenough WT. Environmental Influences on Cognitive and Brain Plasticity During Aging. Journals of Gerontology: Series A: Biological Sciences and Medical Sciences. 2004; 59A(9):940-957.

Kurlowicz, L.; Wallace, M. The Mini Mental State Examination (MMSE). In: Wallace, M., editor. Try This: Best Pracies in Nursing Care to Older Adults. New York: Hartford Institute for Geriatic Nursing; 1999.

Maas M, Buckwalter KC. Providing quality care in Assisted Living Facilities: Recommendations for enhanced staffing and staff training. Journal of Gerontological Nursing. 2006; 32:14-20. [PubMed: 17112134]

Marchant, JAM.; Williams, KN. Memory Matters in Assisted Living. 2009. Manuscript in review

McDougall G. Memory improvement in assisted living elders. Issues in Mental Health Nursing. 2000; 21(2):217-233. [PubMed: 10839062]

Mollica, R.; Johnson-Lemarche, H. State Residential Care and Assisted Living Policy: 2004. 2005. Retrieved May 24, 2007, from http://www.nashp.org

National Center for Assisted Living. Assisted Living Resident Profile. National Center for Assisted Living; 2007.

Radloff LF, Teri L. Use of the center for epidemiological studies-depression scale with older adults. Clinical Gerontologist. 1986; 5(1/2):119-136.

Radloff LS. The CES-D scale: A self-report depression scale for use in the general population. Applied Psychological Measurement. 1977; 1:385-401.

Rebok G, Carlson M, Langbaum J. Training and maintaining memory abilities in healthy older adults: Traditional and novel approaches. Journals of Gerontology Psychological Sciences. 2007; 62B:5361.

Saczynski JS, Willis SL, Schaie KW. Strategy use in reasoning training with older adults. Aging Neuropsychology and Cognition. 2002; 9(1):48-60.

Salthouse TA. Mental exercise and mental aging: Evaluating the validity of the "use it or lose it" hypothesis. Perspectives on Psychological Science. 2006; 1(1):68-87.

Sitzer DI, Twamley EW, Jeste DV. Cognitive training in Alzheimer's disease: A meta-analysis of the literature. Acta Psychiatric Scandinavia. 2006; 114:75-90.

Smith CE, Leenerts M, Gajewski B. A systematically tested intervention to manage a common adverse reactive depression. Nursing Research. 2004; 52(6):401-409. [PubMed: 14639087]

Soon Park N. The relationship of social engagemet to psychological well-being of older adults in assisted living facilities. Journal of Applied Gerontology. 2009; 28:461-481.

Unverzagt FW, Kasten L, Johnson KE, Rebok GW, Marsiske M, Mann-Koepke K, et al. Effect of memory impairment on training outcomes in ACTIVE. Journal of the Interational Neuropsychological Society. 2007; 13:953-960.

Verburgge LM, Jette AM. The disablement process. Social Science Medicine. 1994; 38(1):1-14. [PubMed: 8146699] 
Williams KN. Reasoning exercises in assisted living (REAL): A feasibility study. Issues in Mental Health Nursing. 2008; (29):1-20. [PubMed: 18214774]

Williams KN, Warren CAB. Assisted living and the aging trajectory. Journal of Women and Aging. 2008; 20(3/4):309-327. [PubMed: 18983114]

Williams KN, Warren CAB. Communication in assisted living. Journal of Aging Studies. 2009; 23(1): 24-36. [PubMed: 20107612]

Williams, KN.; Warren, CAB. Memories: Challenges for Assisted Living Residents. 2009. Manuscript in review

Willis SL, Tennstedt SL, Marsiske M, Ball K, Elias J, Mann Koepke K, et al. Long-term effects of cognitive training on everyday functional outcomes in older adults. Journal of the American Medical Association. 2006; 296:2805-2814. [PubMed: 17179457]

Wilson, BA.; Cockburn, J.; Baddeley, A.; Hiorns, R. The Rivermead Behavioural Memory Test Second Edition. In: Company, TVT., editor. Supplement 3: Elderly people. London, UK: Harcourt Assessment; 2003.

Yu F, Kolanowski AM, Strumpf NE, Eslinger PJ. Improving cognition and function through exercise intervention in Alzheimer's disease. Journal of Nursing Scholarship. 2006; 38(4):358-365. [PubMed: 17181084]

Zimmerman S, Scott AC, Park NS, Hall SA, Wetherby MM, Gruber-Baldini AL, et al. Social engagement and its relationship to service provision in residential care and assisted living. Social Work Research. 2003; 27(1):6-17.

Zimmerman S, Sloane PD, Eckert JK, Gruber-Baldini AL, Morgan LA, Hebel JR, et al. How good is assisted living? Findings and implications from an outcomes study. Journal of Gerontology: Social Sciences. 2005; 60B(4):S195-S204. 


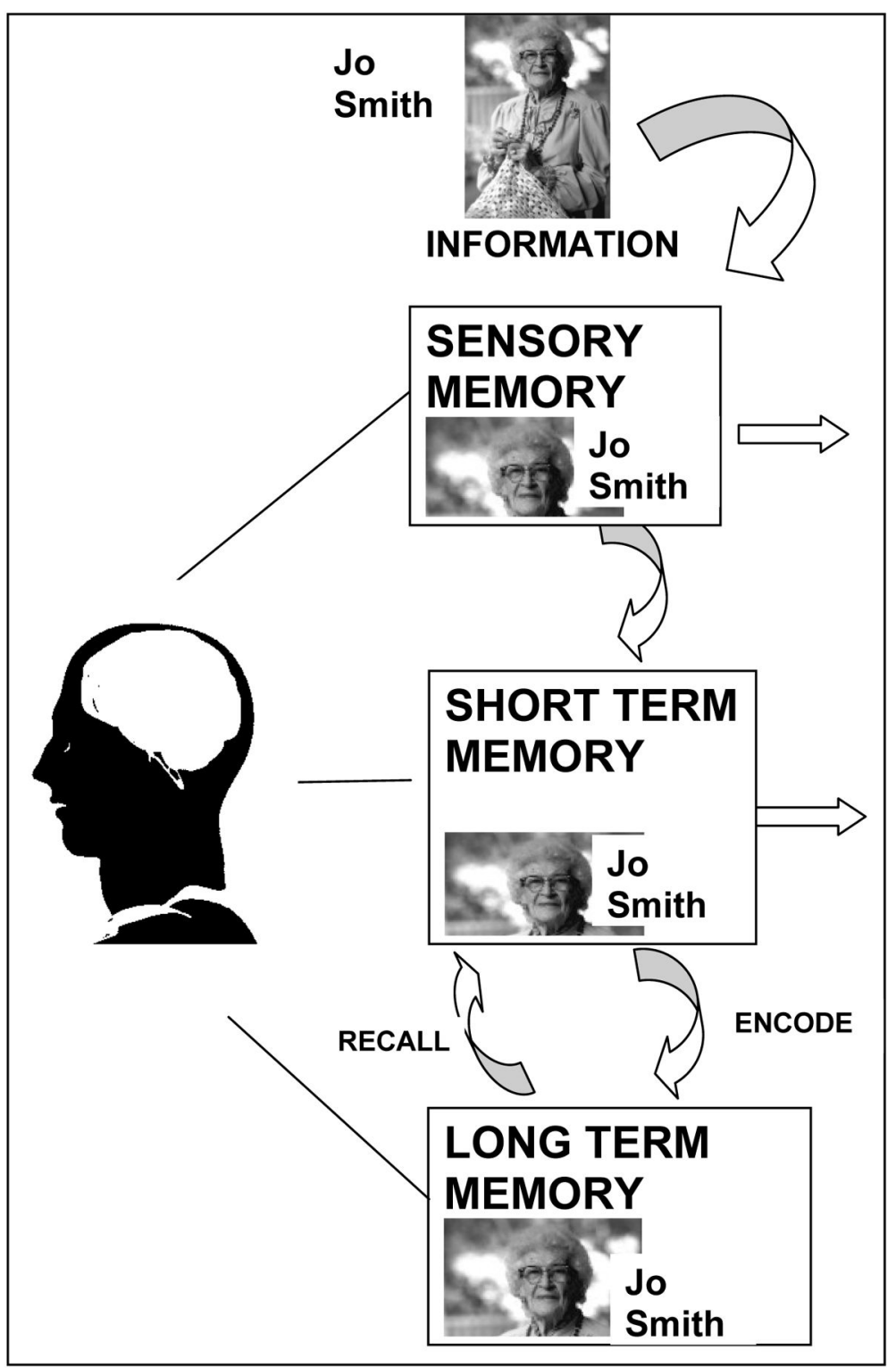

Figure 1.

Diagram of Memory Processing used in MEAL Program. 
The Director of Nursing in your Assisted Living Facility is named Sandy Workman. Create a visual image association to remember her name.

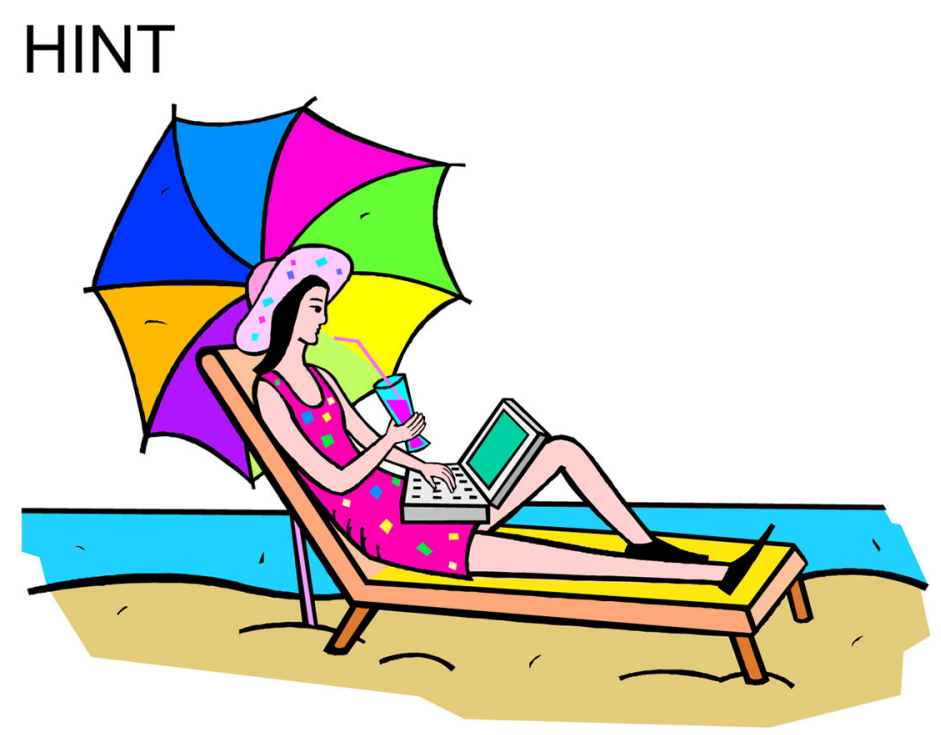

For her last name, you remember how she is always working so hard (and deserves a vacation). You can see her sunning on a Caribbean beach to remember her first name (Sand and Sandra).

Figure 2.

Example of a MEAL Program visual association exercise. 


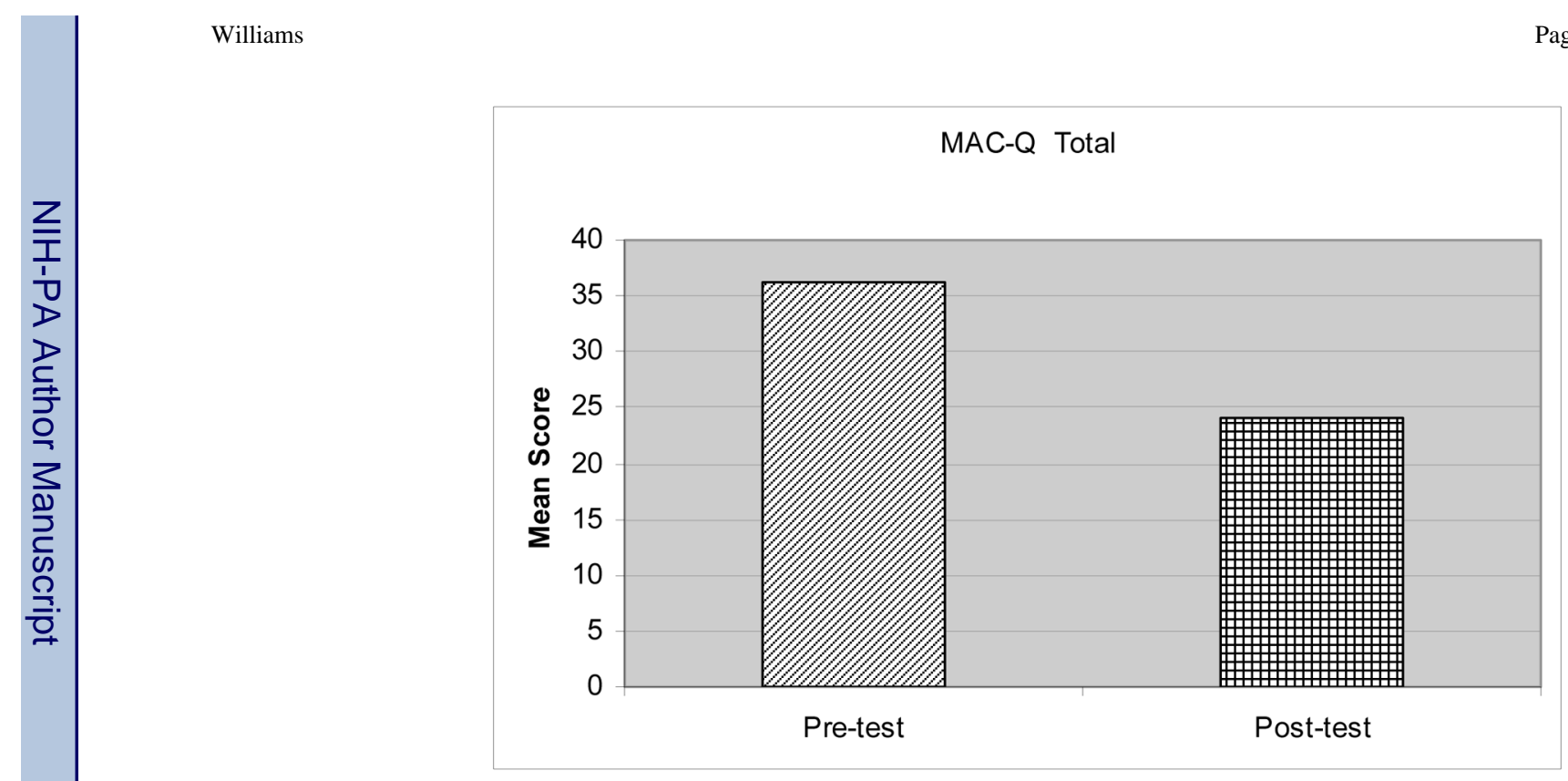

Figure 3.

Comparison of Pre and Post-Intervention Total MAC-Q Scores

Note: Lower scores indicate higher memory self-efficacy. 


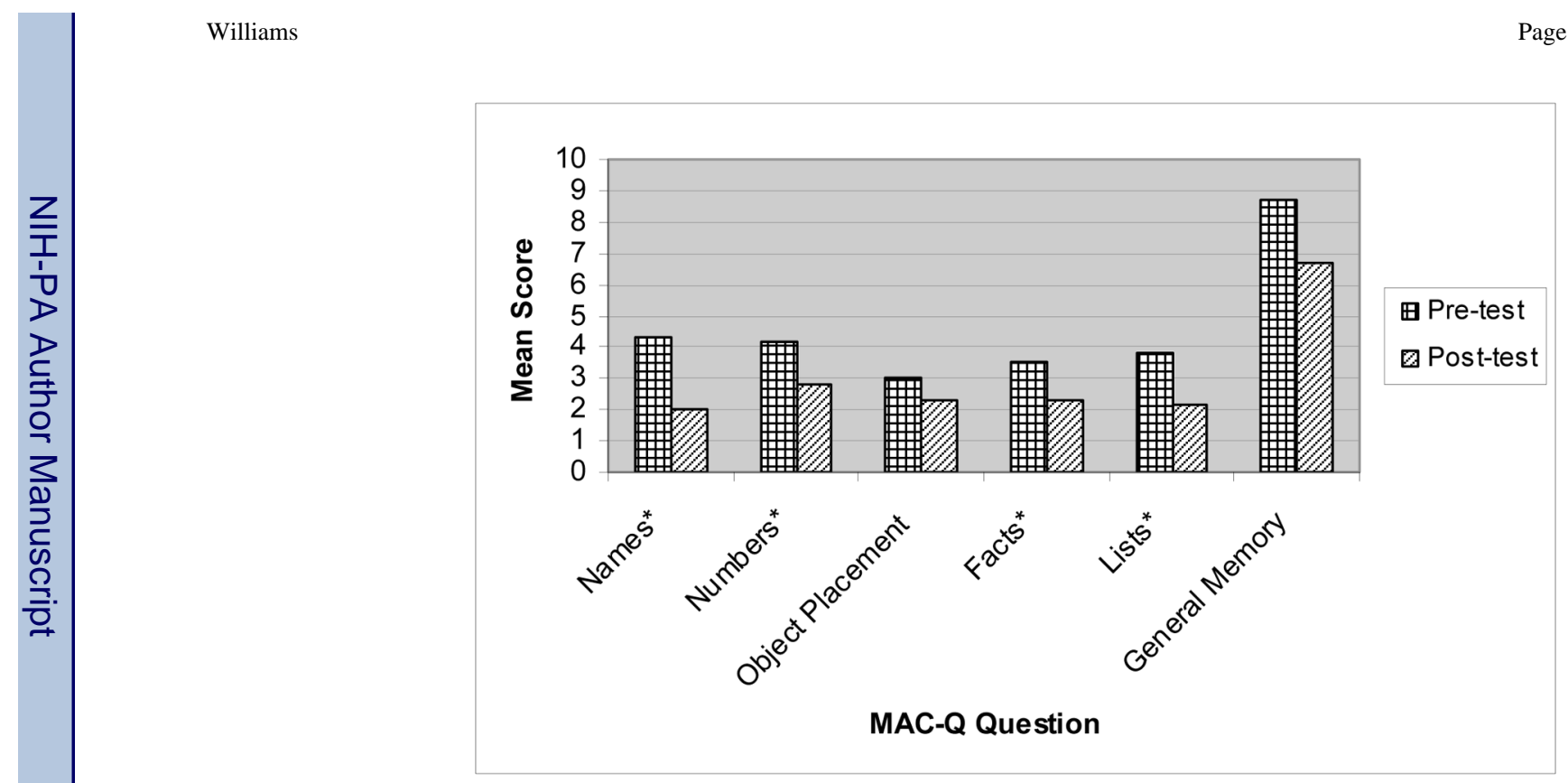

Figure 4.

Comparison of Pre and Post-Intervention Individual MAC-Q Item Scores

Note: Lower scores indicate higher memory self-efficacy. ${ }^{*}$ indicates a significant difference in pre and post-test scores. 


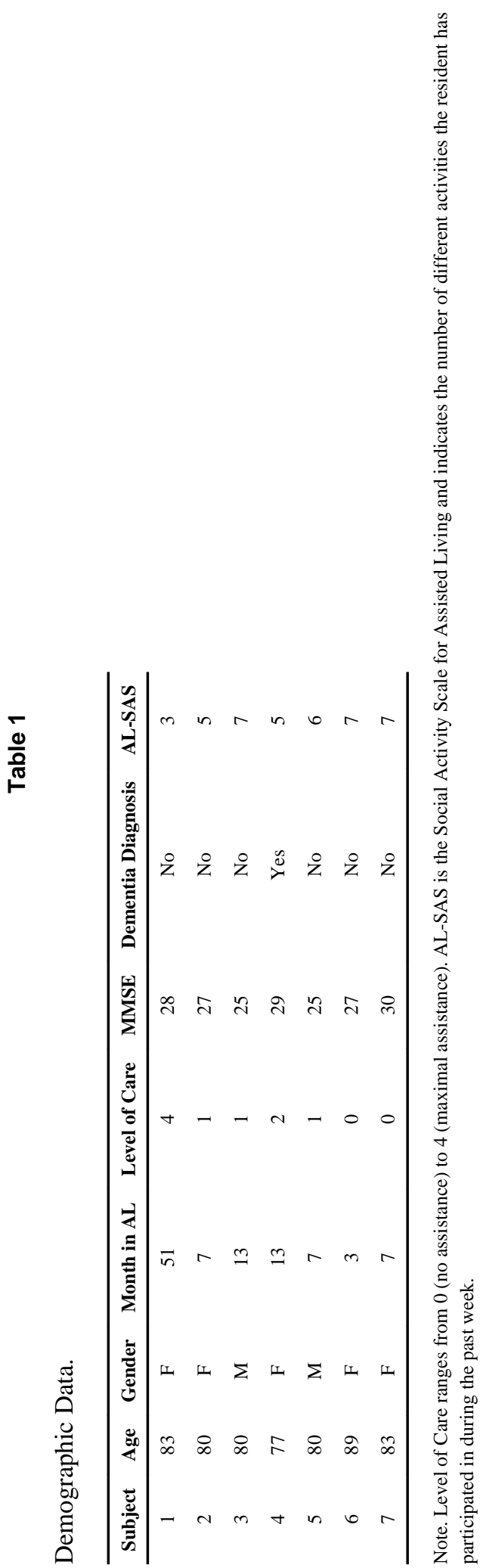

Rehabil Nurs. Author manuscript; available in PMC 2014 October 27. 


\section{Table 2}

MAC-Q Score Comparisons.

\begin{tabular}{|l|c|c|c|c|}
\hline MAC-Q Item & Baseline Mean (SD) Scores & Post-Training Mean (SD) Scores & Z score & Significance (2-tailed) \\
\hline Names & $4.33(.52)$ & $2.00(.9)$ & 2.21 & $.027^{*}$ \\
\hline Numbers & $4.17(.98)$ & $2.83(.40)$ & 1.84 & .066 \\
\hline Object Placement & $3(0)$ & $2.33(1.03)$ & 1.41 & .157 \\
\hline Facts & $3.5(.55)$ & $2.33(.82)$ & 1.89 & .059 \\
\hline Lists & $3.83(.41)$ & $2.17(.75)$ & 2.27 & $.023^{*}$ \\
\hline General Memory & $8.67(1.63)$ & $6.67(2.73)$ & 1.89 & .059 \\
\hline Total Score & $36.17(3.71)$ & $24.0(5.72)$ & 2.37 & $.018^{*}$ \\
\hline
\end{tabular}

Significant at the .05 level 
Table 3

Rivermead Score Comparisons.

\begin{tabular}{|l|c|c|c|c|}
\hline Rivermead Item & Baseline Mean (SD) Scores & Post-Training Mean (SD) Scores & $Z$ score & Significance (2-tailed) \\
\hline First name & $1.0(1.0)$ & $1.29(.76)$ & 1 & .317 \\
\hline Last name & $1.14(1.07)$ & $1.43(.54)$ & 1 & .317 \\
\hline Story immediate & $.86(.69)$ & $1.57(.79)$ & 1.52 & .129 \\
\hline Story delayed & $1.0(1.0)$ & $1.43(.98)$ & .76 & .45 \\
\hline Faces & $1.14(.9)$ & $1.0(.82)$ & .38 & .705 \\
\hline Route immediate & $1.71(.49)$ & $1.57(.54)$ & .58 & .564 \\
\hline Route delayed & $1.43(.97)$ & $1.14(.9)$ & .82 & .414 \\
\hline Orientation & $.57(.54)$ & $1.43(.79)$ & 2.12 & $.034^{*}$ \\
\hline Total Score & $13.71(6.55)$ & $13.86(5.58)$ & .17 & .865 \\
\hline
\end{tabular}

Significant at the .05 level 